\title{
48. UNDERWAY GEOPHYSICAL MEASUREMENTS, LEG 42B
}

\author{
Yuri P. Neprochnov, P. P. Shirshov Institute of Oceanology, Academy of Sciences, USSR
}

\section{INTRODUCTION}

Echo sounding, magnetic measurements, and continuous seismic profiling (CSP). were made from D/V Glomar Challenger, on Leg 42B, between drill sites, at a speed of about 10 knots (Figure 1). Seismic profiling was made using a Bolt pneumatic source, usually with two airguns, one 10 and one 40 in. $^{3}$ Recording of returns was generally made in the frequency band of 40 to $60 \mathrm{~Hz}$ at two time scales: 5 and 10 sec. The seismic profiling data shown here are photocopies from the original 5 -sec record.

Magnetic field measurements were made using a proton magnetometer of the "Varian" type. The magnetic data were prepared and edited (listed by 5min intervals) on shore by the Geological Data Center of Scripps Institution of Oceanography. The bathymetric data were reduced on shore by the same method (Figure 2).

\section{BOSPORUS TO SITE 379}

The track from the Bosporus to Site 379 was almost straight. It crossed the shelf and continental slope of the Black Sea Basin and proceeded along the foot of the slope and basin apron to the central part of the basin (Figures 1 and 2).

The continental slope along the profile is very steep. Its upper part resembles a scarp because the sedimentary layers on the edge of the shelf are sharply terminated (Figure 3). The lower part of the slope is irregular. Sediments on the apron are folded and faulted with some evidence of slumping. The magnetic

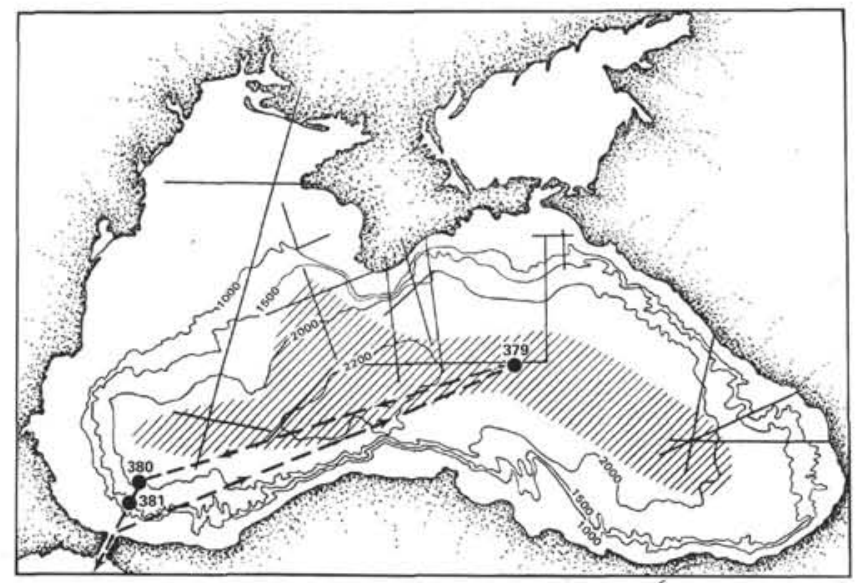

Figure 1. Track of Glomar Challenger (solid dotted lines). The thin straight lines are the profiles of Deep Seismic Sounding made by U.S.S.R. The dashed area is the region of suboceanic crust. field in this area is also variable, but not as irregular as the topography.

The major part of the profile is in the deep-sea basin and shows a flat floor at the depth of about 2200 meters. Seismic penetration was to a depth of 0.5 to 1.0 $\mathrm{km}$, assuming a sediment velocity of $2.0 \mathrm{~km} / \mathrm{sec}$. Near the edge of the basin apron and its mergence with the abyssal plain, the sediments consist of two units. The upper unit, about $0.2-0.5 \mathrm{~km}$ in thickness, is well stratified and the layers are almost horizontal. The lower unit is broadly folded, especially near the central part of this profile. The folded zone may be the western extension of similar ridges and folds found in the south central part of the Black Sea Basin (Goncharov et al., 1972). This area also has a strong magnetic anomaly (Figure 2). At the northeastern end of the profile, in the area of Site 379, the sediment layers are thin with some small, broad folds indicated at depth. The magnetic field in this area is relatively smooth.

\section{SITE 379 TO SITE 380}

This profile went from the flat bottom of the deep basin gradually upwards towards the shallower (by about $100 \mathrm{~m}$ ) Site 380.

Seismic penetration was about $1 \mathrm{~km}$ (Figure 4). As in the preceding profile, the upper $0.2-0.3 \mathrm{~km}$ of sediments consist of thin flat-layered units and the lower portion shows evidence of broad-scale folding. Small-scale vertical faults (with only a few meters displacement) are observed along much of the profile. There are no distinctive individual reflectors on the profile. Nevertheless, the section shows a general thinning in the direction of the continental slope.

The magnetic field along the profile is relatively smooth and only shows relief near Site 380 .

\section{SITE 380 TO SITE 381}

The bottom topography rises from 2100 to 1700 meters towards Site 381. In the area of Site 381 a small survey was made to choose the eventual site. As seen from the seismic record (Figure 5), all reflectors rise and some layers pinch out in the direction of Site 381 .

\section{ACKNOWLEDGMENTS}

The data were collected at sea by the DSDP technicians under the direction of J. Bode; their important contribution is gratefully acknowledged. The seismic profiles and bathymetric and magnetic computer plots were processed by the staff of the Geological Data Center of the Scripps Institution of Oceanography.

\section{REFERENCE}

Goncharov, V.P., Neprochnov, Y.P., and Neprochnova, A.F., 1972. The bottom relief and deep structure of the Black Sea Basin: Moscow (Nauka). 

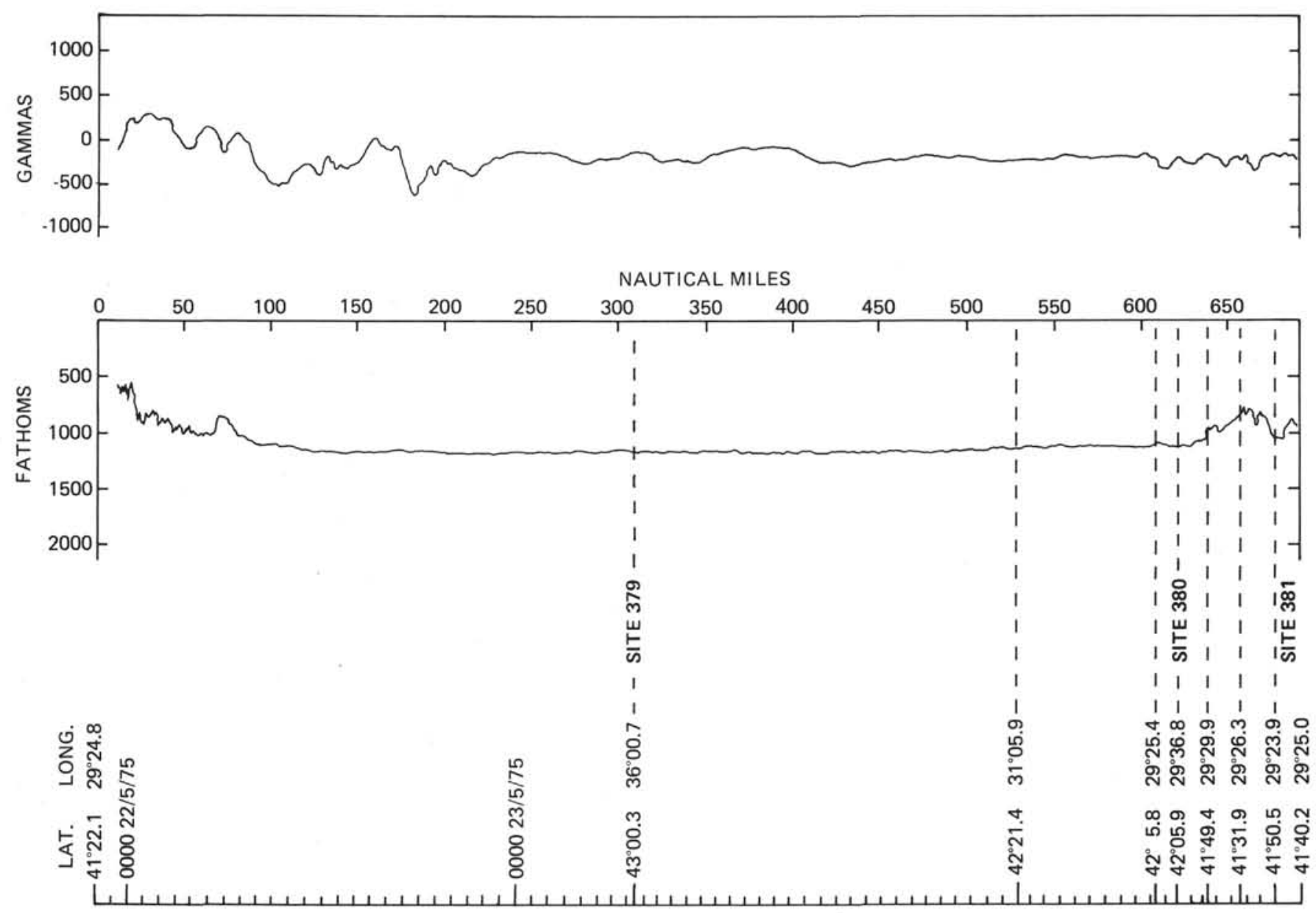

Figure 2. Underway bathymetry and magnetic data collected in Glomar Challenger's Leg 42B. 


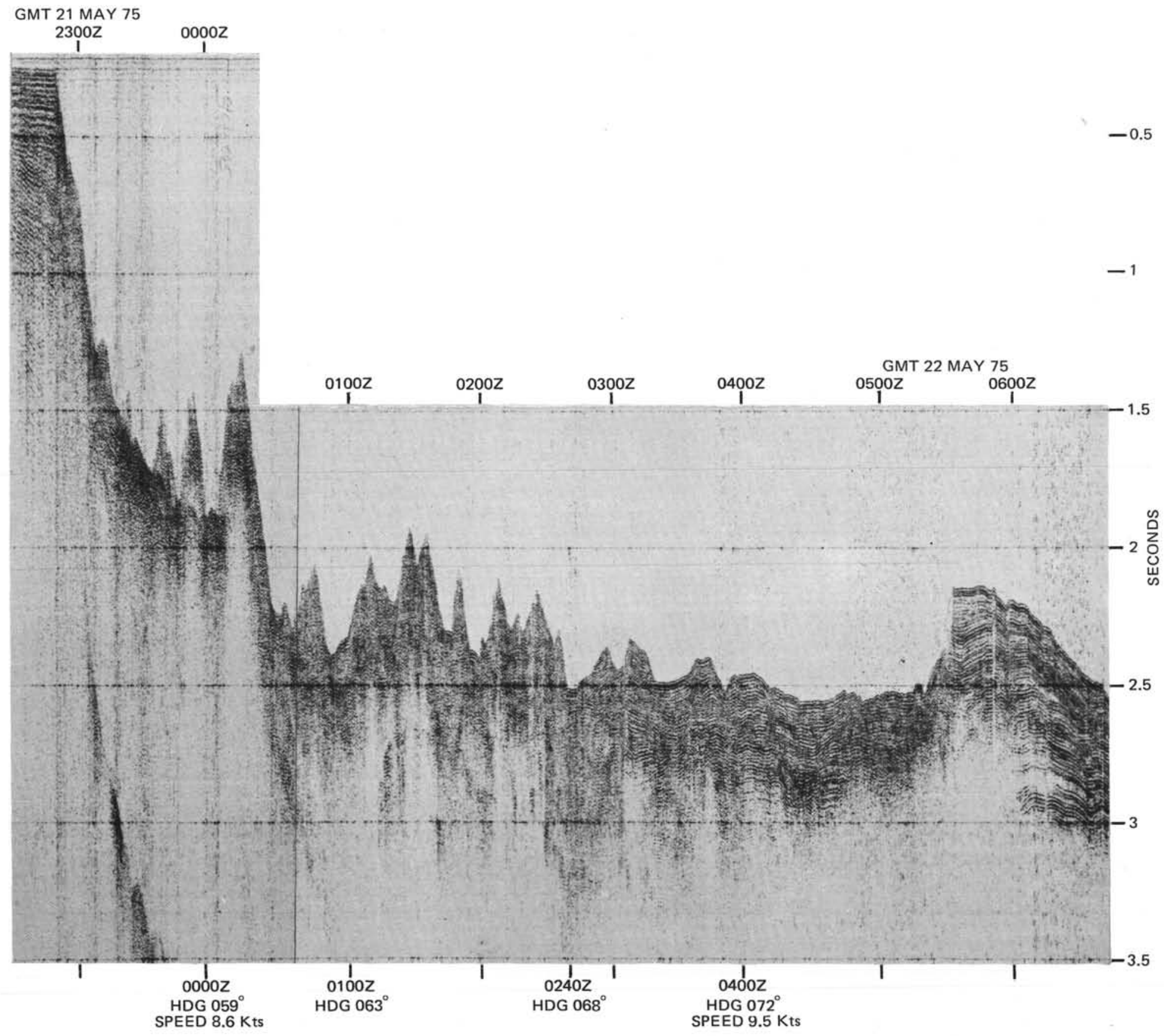

Figure 3. Seismic profile from Bosporus to Site 379. 


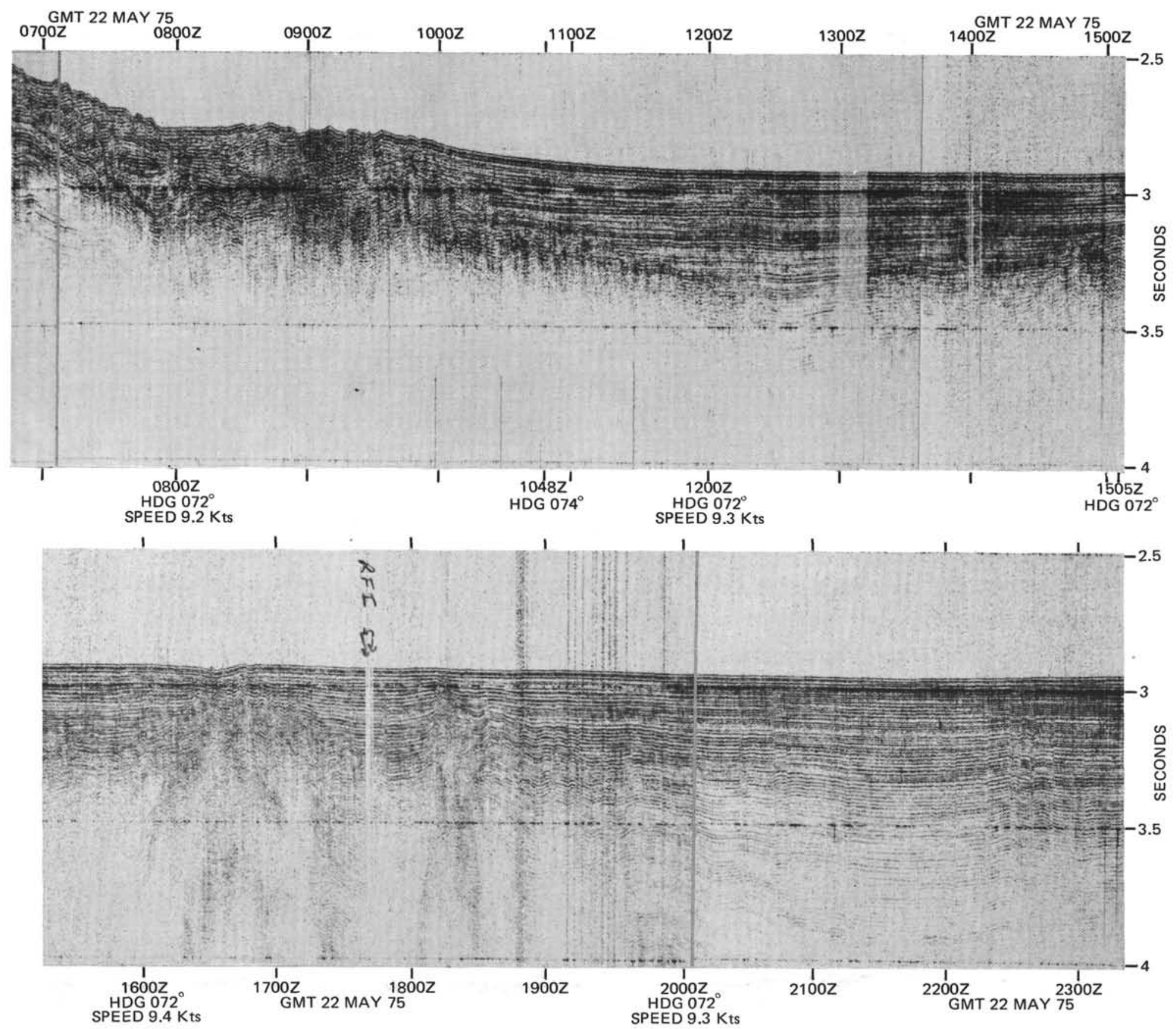

Figure 3. (Continued). 


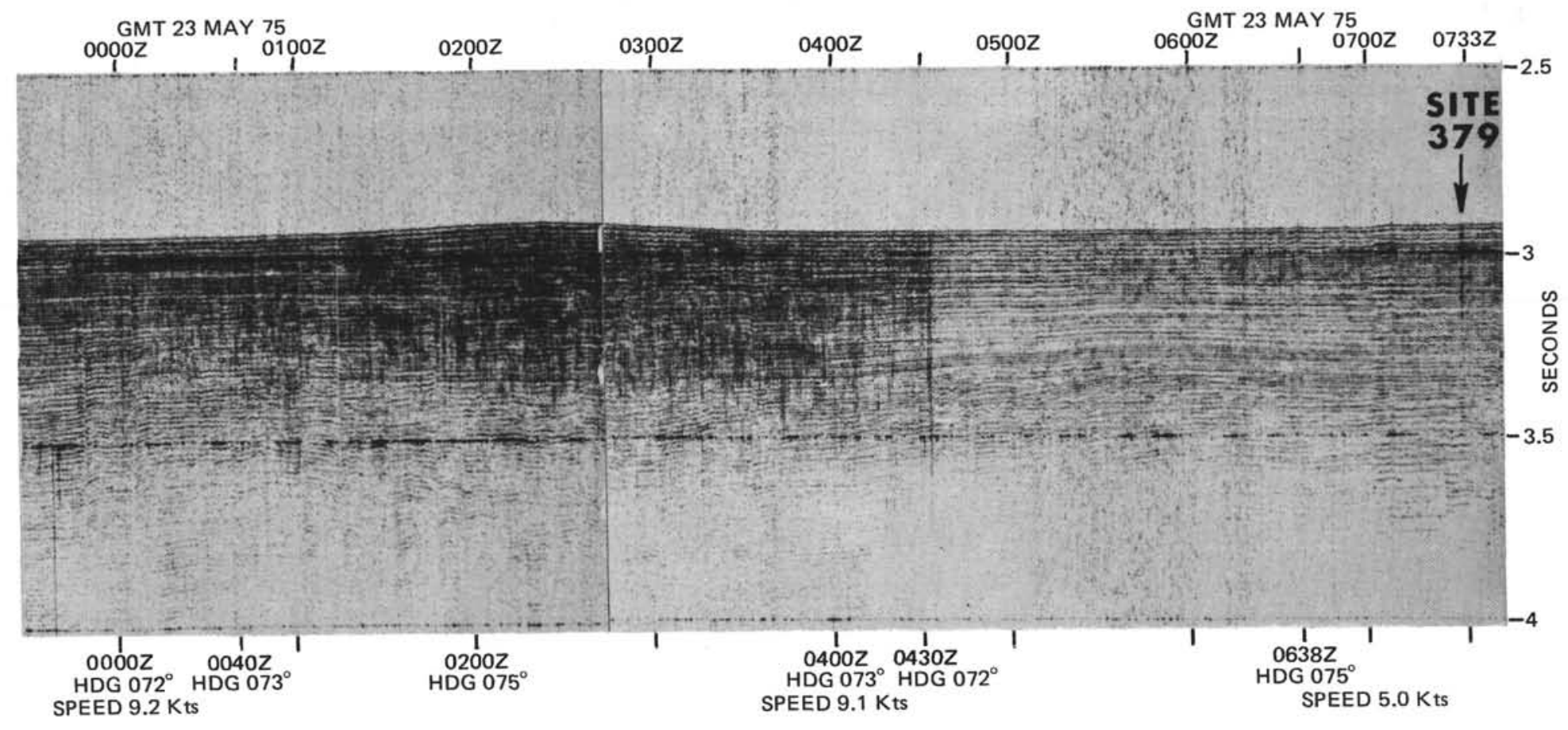

Figure 3. (Continued). 


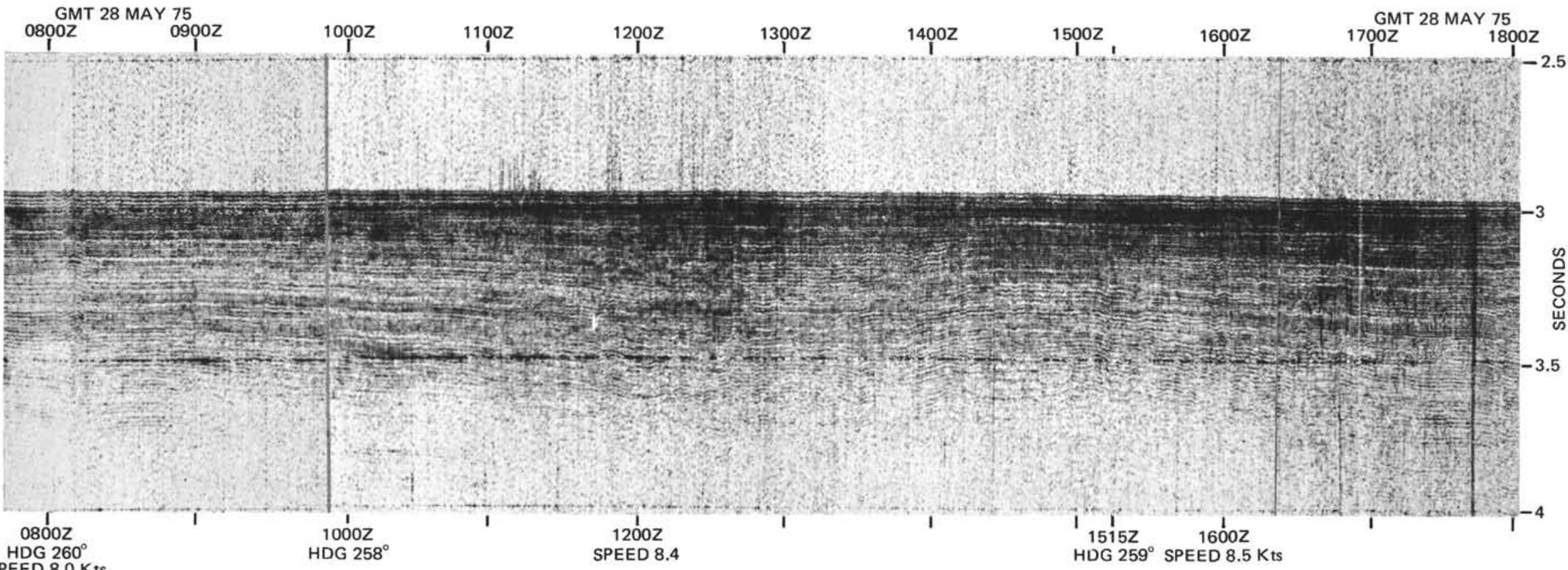
HDG $260^{\circ}$
SPEED $8.0 \mathrm{~K}$ ts

00002 $1515 z$
HDG $259^{\circ}$ SPEED $8.5 \mathrm{Kt}$
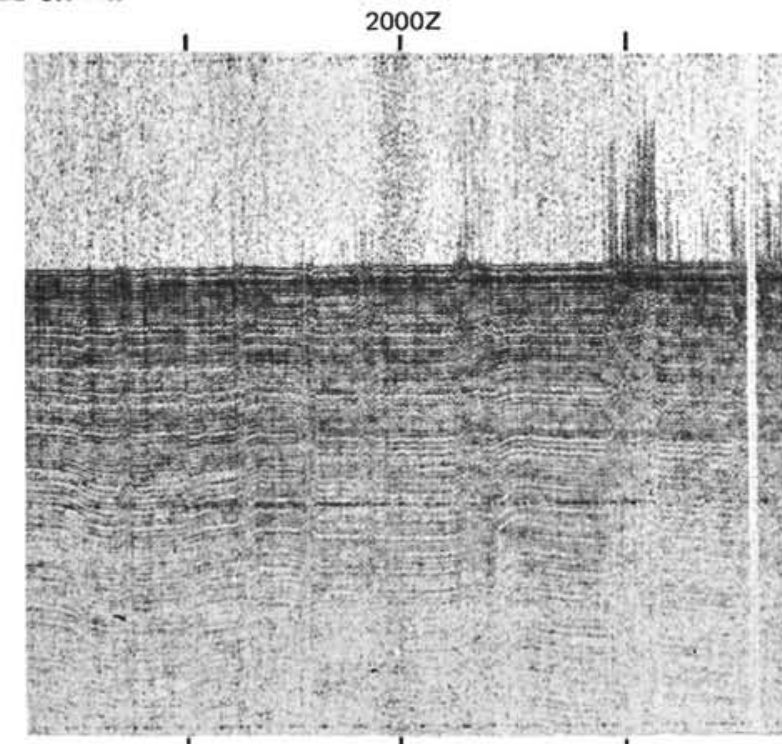
$2200 Z$ $1200 Z$
SPEED 8.4

$1900 Z$

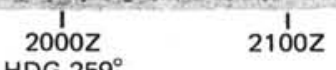
SPEED $8.7 \mathrm{Kt}$

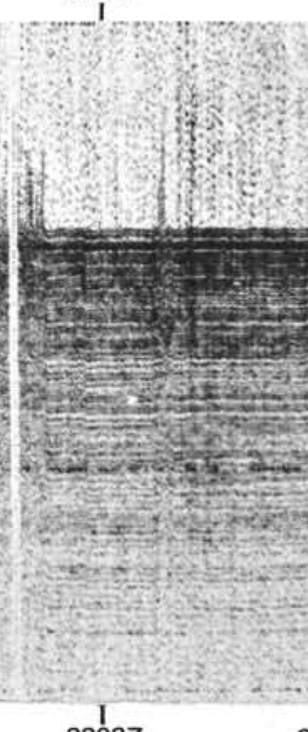

$2202 Z$
$H D G 261^{\circ}$

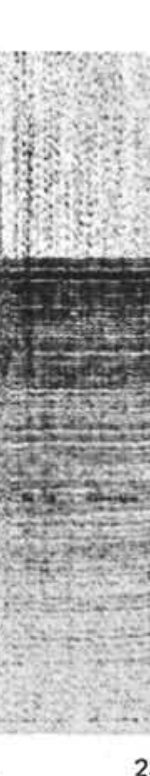

$2300 z$

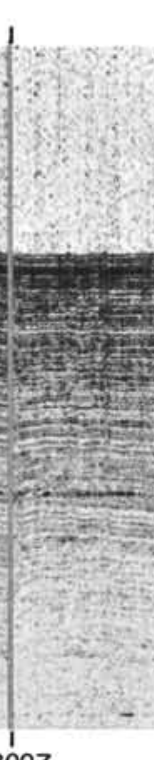

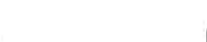

traxt

$0400 z$ $-2.5$

Figure 4. Seismic profile from Site 379 to 380. 


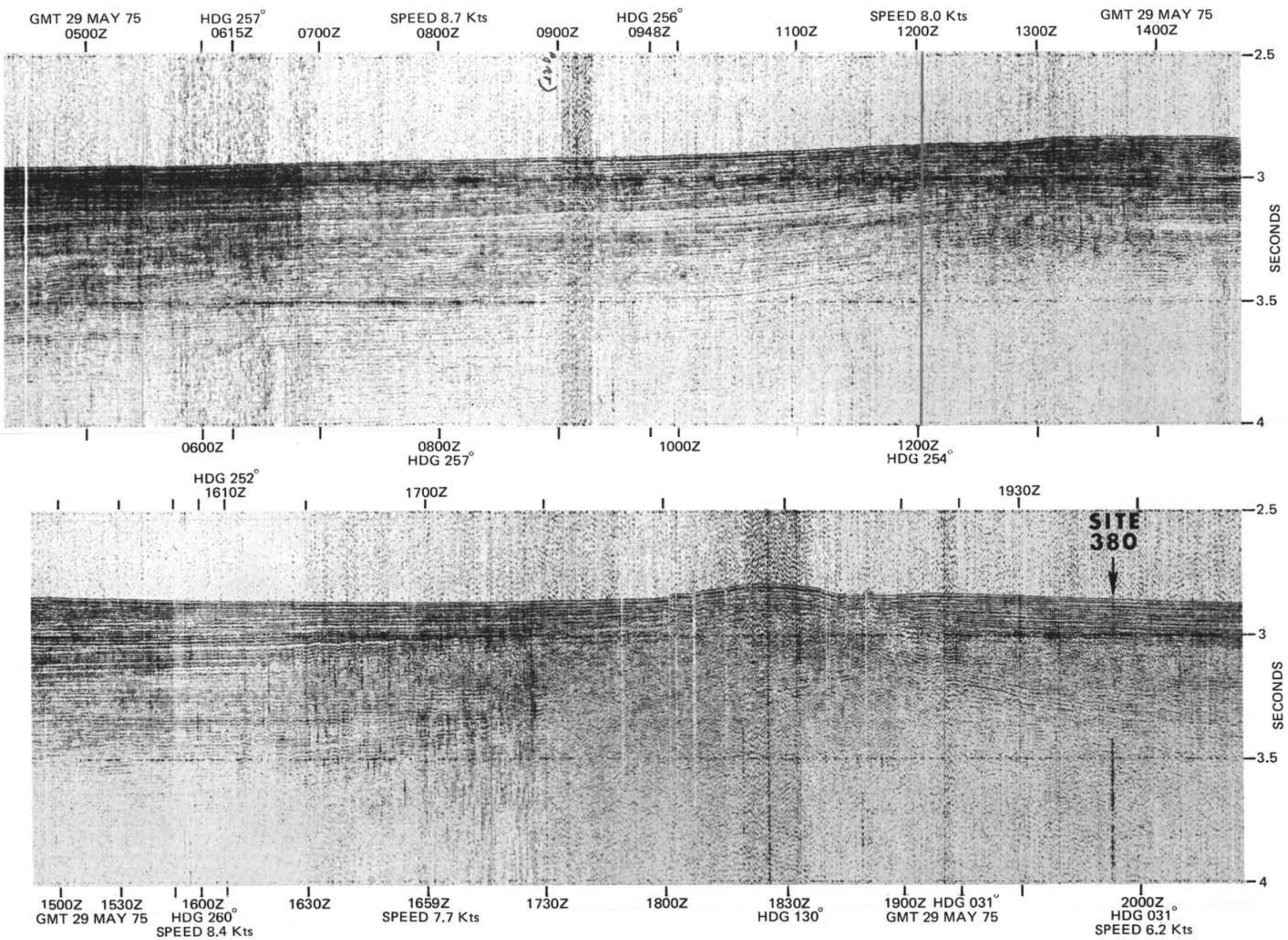



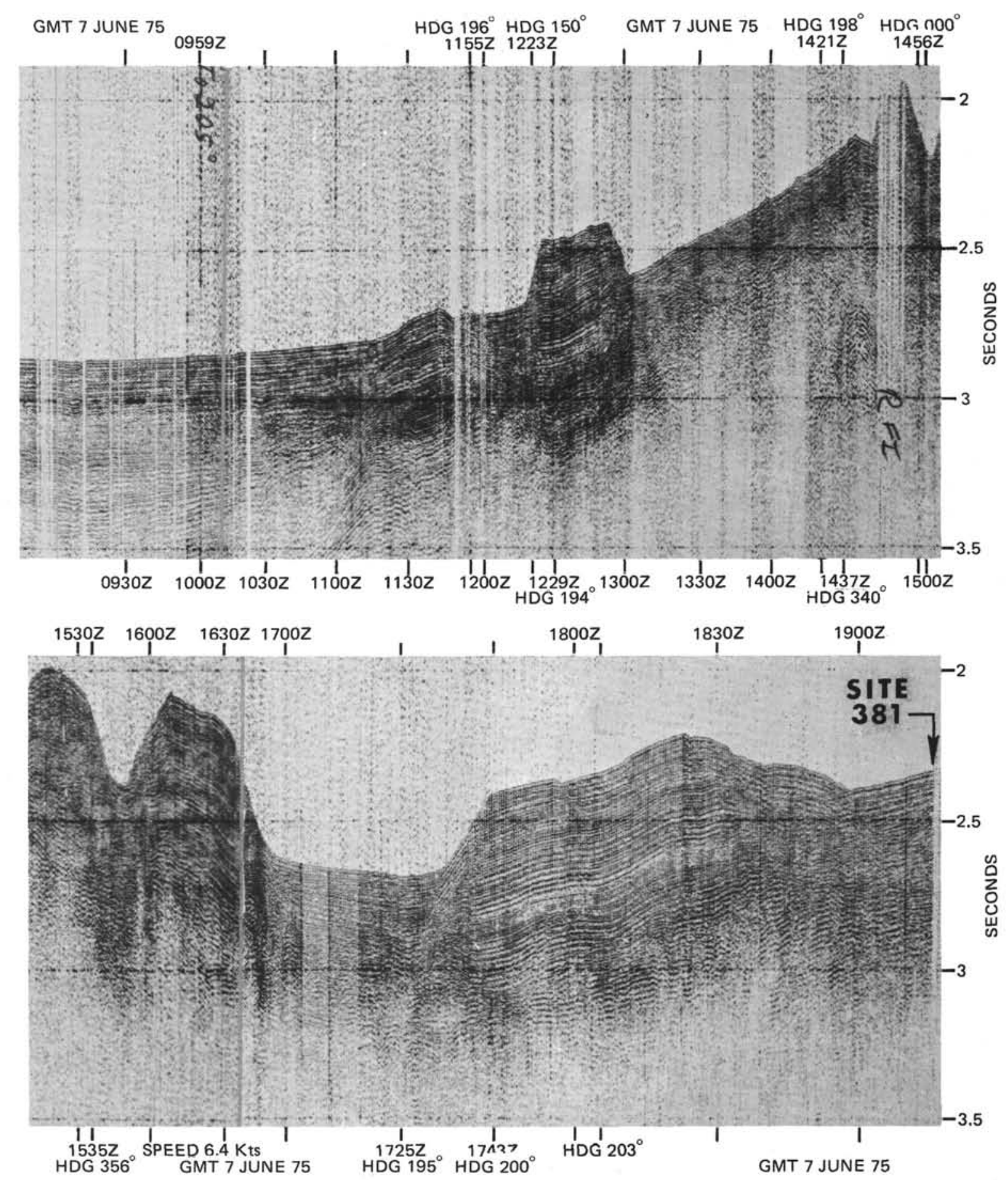

Figure 5. Seismic profile from Site 380 to Site 381 and survey in Site 381 area. 